\title{
A methodology for the assessment of multiple benefits of industrial energy efficiency measures
}

\author{
Claas Wagner $^{1} \cdot$ Melissa Obermeyer $^{1} \cdot$ Richard Lüchinger $^{1}$
}

Received: 28 October 2019 / Accepted: 17 January 2020 / Published online: 25 January 2020

(c) Springer Nature Switzerland AG 2020

\begin{abstract}
Industrial energy efficiency measures are proving financially viable, but the implementation rate is stagnating. This results in the need to develop a comprehensive and standardized methodology to assess the multiple benefits of energy efficiency measures in an industrial context. However, a comprehensive methodology to assess the multiple benefits of energy efficiency measures are omitted. The methodology, as presented in this study, was developed and validated based on nine case studies performed between 2016 and 2018 in the Swiss industrial sector. The aim is to close this gap with the introduction of a three-phase standard methodology, applicable to a wide range of industrial processes and energy efficiency measures. The three phases are further split into individual steps, each pursuing a specific goal in order to facilitate the implementation of energy efficiency measures. The first phase, the delimitation, aims at defining the system boundaries of the considered industrial process(es). The second phase, the assessment, involves the identification, the quantification, and the monetization of multiple benefits, as well as the qualitative assessment of non-monetizable multiple benefits. The last phase, the evaluation, focusses on the integration of the obtained results into the financial valuation of the energy efficiency measure and, therefore, on the cash flow analysis and the determination of the payback time under consideration of the monetizable multiple benefits. The study has shown that the consideration of monetizable multiple benefits may reduce the payback time of energy efficiency measures by up to $40-85 \%$.
\end{abstract}

Keywords Non-energy benefits · Multiple benefits · Energy efficiency measures · Full-cost analysis · Industrial processes

\begin{tabular}{ll}
\multicolumn{2}{l}{ Abbreviations } \\
$\mathrm{CO}_{2}$ & Carbon dioxide \\
$\mathrm{EEM}$ & Energy efficiency measure \\
$\mathrm{EU}$ & European Union \\
$\mathrm{KPI}$ & Key performance indicator \\
$\mathrm{MB}$ & Multiple benefits \\
$\mathrm{SCCER}-\mathrm{EIP}$ & Swiss Competence Centres for Energy \\
& Research-Efficiency of Industrial \\
& Processes \\
$\mathrm{CCPE}$ & Competence Center Power Economy \\
$\mathrm{IEA}$ & International Energy Agency \\
$€$ & Euro \\
$€ / \mathrm{a}$ & Euro per year \\
$\mathrm{kWh}$ & Kilowatt-hours
\end{tabular}

$\begin{array}{ll}\text { kWh/a } & \text { Kilowatt-hours per year } \\ \text { MWh } & \text { Megawatt-hours } \\ \text { MWh } & \text { Megawatt-hours per year } \\ \mathrm{t} & \text { Ton } \\ \mathrm{t} / \mathrm{a} & \text { Tons per year }\end{array}$

\section{Introduction}

In Switzerland, the energy demand of the industrial and the service sector accounts for approximately $40 \%$ of the total energy demand. The Swiss Federal Council plans to reduce energy consumption by $20 \%$ and the $\mathrm{CO}_{2}$ emissions by $40 \%$ until 2050 . To support the achievement of

Claas Wagner, claas.wagner@hslu.ch | Institute for Innovation and Technology Management, Lucerne University of Applied Sciences and Arts, Lucerne, Switzerland. 
these goals, the Swiss Competence Centers for Energy Research-Efficiency of Industrial Processes (SCCER-EIP) have been conducting research in this area since 2014. The Competence Center Power Economy (CCPE) at the Lucerne University of Applied Sciences and Arts-Engineering and Architecture, have been involved in Work Package 1 of the SCCER_EIP research, which focuses on the implementation of industrial energy efficiency [1]. The main goal of the CCPE is to facilitate the realization of energy efficiency measures (EEM) in the industry by providing a standardized methodology that includes multiple benefits (MB) in the investment evaluation. By holistic consideration of all relevant costs, the implementation of EEM should be made more attractive for the industry sector.

Based on data from 2015, the industrial energy demand of the EU-28 fell by $15.5 \%$ in the period between 2007 and 2015 [2]. However, the industry still accounts for roughly $25 \%$ of the total energy demand of the EU-28 [2]. The greenhouse gas emissions of the EU-28 yielded a total of 4'300 million tons of $\mathrm{CO}_{2}$ equivalents in 2015, of which approximately $9 \%$ can be traced back to industrial processes [3]. As part of the second obligation period, as well as in the course of the European Climate- and Energy Package, the EU plans to reduce their greenhouse gas emissions by $80-95 \%$ (based on the values of 1990) until 2050 [3]. In Switzerland, the share of the total energy consumed by industry is $18.5 \%$ [4], while Switzerland's total greenhouse gas emissions account for 48 million tons of $\mathrm{CO}_{2}$ equivalents, of which $22 \%$ are caused by industrial processes [5]. In addition to the 2016s Paris agreement, Switzerland plans to reduce its greenhouse gas emissions by $70-85 \%$ (based on the values of 1990) until 2050 [5]. To achieve these goals the three main sectors, households, transport, and industry, need to drastically reduce their energy consumption as well as their greenhouse gas emissions. However, the industry, which is the focus group of this study, does not yet adopt EEMs to the extent necessary [6].

For this study, the term "energy efficiency measure" was defined as follows: The main aim of an EEM, independent of its functionality, is to reduce the amount of energy consumed for a particular task or process by using the available energy more efficiently. Therefore, a system is considered an EEM when it reduces either; the total energy consumption, the total emissions of $\mathrm{CO}_{2}$ equivalents, or when it operates on a renewable energy carrier as a substitution of fossil fuels. This description results in the assumption that almost every system, which operates more energy efficient than its predecessor, can be considered an EEM. However, according to the International Energy Agency (IEA), an enhanced energy efficiency tends to be viewed by industry as a by-product of initiatives undertaken for business reasons and is rarely a targeted purpose
[7]. On the one hand, this appears to be due to numerous barriers, such as low energy prices, lacking awareness of management or complex implementation, which hinder the realization of an EEM [8-11].

On the other hand, the relevant critical financial indicators of EEMs are generally computed based on the monetized yearly energy savings only, which were found to yield often-unfavorable payback times. Therefore, EEMs often do not undergo a complete full-cost analysis, such as other projects with a more significant impact on the core business activities of an organization [7]. As such, the potential of revealing all positive cash flows associated with the implementation of EEMs remains untapped, and the investment appears unfavorable to decision-makers.

This paper intends to show that there are MB based on EEMs and that they are quantifiable to a certain degree. If $M B$ are included in a full-cost calculation, the payback time of the investment can be reduced. This insight should, in turn, lead to an increase in the implementation in EEM in industry.

\section{Literature review}

The purpose of the literature review is threefold: The literature research was essential to show the entire subject, the state of the art of the associated research, as well as the interdependencies of MBs and EEMs in industrial applications. In addition, the research was used directly to obtain relevant facts and figures, those of the conceptual development of the MB methodology. In addition to these two main objectives of literature research, the need for a standardized MB methodology can thus be clarified. For this study, the term "multiple benefits" was defined following the description of Mills and Rosenfeld [12], who stated that $\mathrm{MB}$ are capable of adding value and enhancing the energy services delivered by efficient technologies. In literature, the terms non-energy benefits or additional benefits are also frequently used instead of the term MB.

Research activities concerning the facilitation of the realization of EEMs as well as concerning strategies to simplify the communication with decision-makers inside organizations have taken place since the early eighties [13]. Research communities became more aware of the concept of $\mathrm{MB}$ in the early nineties, which was the actual starting point for intensified research in terms of $M B$ of EEMs in the industry.

Lilly and Pearson [14], analyzed five cases of installed EEMs in industrial processes in terms of energy savings and peak demand and assessed related MB to conduct cost-benefit analyses from different stakeholder perspectives. They approached the analyses by firstly identifying the associated non-energy impacts with the aid of plant 
management and operations staff. Subsequently, they collected pre- and post-retrofit data to quantify the identified impacts, which resulted in $24 \%$ of the total cash savings. Moreover, Lilly and Pearson [14] found out that $81 \%$ of the customer's non-energy savings were the result of reduced operation and maintenance expenses. Based on several case studies, Pye and McKane [15] identified a set of MB, such as reduced production costs, improved capacity utilization, or improved worker safety. They found that MB often exceed the value of pure energy savings.

Worrell et al. [16] reviewed the relations between energy efficiency improvements and productivity on the base of more than 70 industrial case studies from different sectors. They were amongst the first to propose a methodology to systematically include the identified productivity benefits in the economic assessment of the potential for EEMs in the industrial sector. The methodology, as proposed by Worrell et al., consists of four distinct steps: (1) identification and description of the MB associated with a given measure,(2) quantification of the impacts; (3) identification of assumptions; (4) calculation of the cost impacts of the productivity benefits. However, they suggest paying particular attention to how the related limits of this method are managed to assure the robustness of the analysis. In the same year, Hall and Roth [17] analyzed 74 interviews concerning MB research from which they found that most interview partners linked significant value with $M B$, which was rated by far higher than the value of the actual energy savings of an EEM. Lung et al. [18] conducted further research on the importance of ancillary savings and production benefits in industrial facilities based on 81 case studies by applying the same approach as Worrell et al. [16]. They described that common payback models for assessing the usefulness of energy efficiency efforts include simple payback, net present value (rate of return) and internal rate of return [18]. Moreover, they highlighted that intangible ancillary savings could not be included in the economic assessment due to difficulties concerning their quantification. Skumatz et al. [19] reviewed a large number of conference papers and interviewed many professional researchers, from which they found that MB are often considered "hard to measure" effects. Furthermore, they state that a large share of literature in the last decade has focused on methods to measure MB with the outcome that more than a dozen measurement approaches have been developed.

In 2011, Cooremans researched decision-making mechanisms in the industrial sector and claimed that the strategic nature of the investment is more vital than profitability [20]. In a follow-up paper, Cooremans [21] then proposed three reasons why energy efficiency investments are not decided upon by profit-seeking firms: (1) EEMs have a low real profitability,(2) information problems prevent price indications from reaching decision-makers; and (3) EEMs force organizations to define sub-optimal routines. Ryan and Campell [22] discussed the implications the assessment of MB has on energy efficiency policies as a part of a broader socioeconomic strategy. They concluded that the improvement of the cost-benefit assessment of energy efficiency programs might help decision-makers reconcile perceived trade-offs between supporting economic growth and reducing energy use.

Rasmussen [6] stated that the dragging implementation of EEMs in the industry could be traced back to the fact that not all benefits are included in the evaluation of energy-efficiency investments. She, therefore, suggested a consistent definition and categorization of benefits related to industrial energy efficiency. The IEA [7] conducted an extensive review of the state-of-the-art of quantifying $M B$ of energy efficiency in which more than 300 people from 27 countries and over 60 organizations were involved. One of the critical challenges that are described in the section "Industrial sector impacts of energy efficiency" [7] of the IEA report, is the high heterogeneity of the industrial sector: there are thousands of different industrial processes and therefore, countless ways in which energy efficiency projects can be designed and implemented. The study concluded that a MB approach recognizes the role of energy efficiency as a fundamental enabler of economic and social development. More comprehensive consideration of the various positive but also negative impacts will assist in deciding on how to allocate resources [7].

Russell [23] found out that the inclusion of MB in the investment analysis can reduce the payback time of EEMs by roughly $50 \%$. Moreover, he concluded that the MB of industrial EEMs are situational and appear to be unique for a given facility configuration. Nehler and Rasmussen [24] investigated investment motives and critical aspects of adopting energy-efficiency in investments based on a series of surveys and interviews, conducted amongst Swedish industrial companies. Nehler [25] reanalyzed the same series of surveys and interviews, from which she found that only a few MB were translated into monetary values and included in the investment evaluation. She generalized these findings and further emphasized the importance of a system-perspective to understand all the effects of EEMs and their associated MB.

In 2017, Rasmussen published a follow-up paper titled, "The additional benefits of energy efficiency investments - a systematic literature review and a framework for categorization" [26], further elaborating on the same issues as in the previous paper [6]. Therein she states that financial evaluations methods are often addressed in the content of investment decision-making for energy efficiency investments, often involving capital budgeting tools such as net present value and internal rate of return, as well as 
calculating a payback [26]. Based on literature research, she found that energy efficiency investments are hindered by limited access to capital, a perceived slow return, and inconsideration of energy as an essential issue. She further suggests that, in contrast to most studies that propose an ex-post analysis of NEBs, an ex-ante analysis should be preferred in order to increase the profitability of planned investment. Therefore, she introduces a framework to classify NEBs according to their degree of quantifiability (low, medium, high) and their timeframe in which they potentially occur (short term, long term). Cagno et al. [27] conclude that more profound knowledge of the impacts related to an EEM could more effectively lead to an amplified understanding of the barriers behind the adoption of an EEM. This aspect is closely linked to decision-makers who need a much broader perspective on the full range of possible impacts of introducing an EEM.

For a profound understanding of the $\mathrm{MB}$, as well as the understanding of the decision-making processes within the target organizations, it is also important to understand the drivers that promote the implementation of EEMs, as well as the obstacles that hinder the implementation of EEMs. In 2013, the Zurich University of Applied Sciences [9] carried out an extensive literature review focusing on the findings of various studies concerning drivers and barriers of the implementation of EEMs in large, medium and small companies (SME) mostly within Europe. In their study, they state that one of the findings of multiple studies was the importance of calling attention to energy efficiency programs in as many SMEs as possible, in order to be able to realize these programs successfully. However, the average implementation rate of EEMs in SMEs appears to be no more than $50 \%$ across different industry sectors and investigated programs.

Cagno et al. [27] describe in their paper the effect of drivers on barriers in the decision-making process steps, based on an exploratory investigation into small and medium-sized enterprises. In their study, they showed that economic barriers, followed by behavioral as well as awareness, emerged as critical issues, especially for smaller and non-energy intensive companies. Information about real energy costs, public investment subsidies, as well as clarity and trustworthiness of information, emerged as quite relevant drivers in average terms. In addition, they highlighted the relevance of both internal and external drivers.

Haraldsson and Johansson [28] studied the importance of different barriers and drivers for improved energy efficiency in the Swedish aluminum industry. The data was collected through a questionnaire divided into different categories, covering 39 barriers and 48 drivers.. They considered technological and economic barriers as the most important categories. The most important categories of drivers were the organizational and economic drivers. They recommended that companies provide education for their employees to improve their knowledge regarding their company's processes, operations and EEMs.

A message that is conveyed by almost all literature is the presumed complexity of a structured approach to quantify and monetize $\mathrm{MB}$ in the industrial sector. Over the years, each study seemed to go a small step further, proposing another bit of a methodology to quantify, or at least categorize, the different MB arising from various EEMs. However, to date, there is no comprehensive solution or method to counteract the low implementation rate of EEMs in industrial settings. It is vital to provide a comprehensive methodological solution, which can be applied by the industry to accelerate and support the trend towards improving energy efficiency.

\section{Development of the MB methodology}

The following section elaborates on the approach with which a comprehensive methodology is used to identify, quantify, and monetize the MB of industrial EEMs-the MB methodologies-has been developed. Moreover, it explains the elements the methodology is based on and how it has been and can be applied in industry.

The assessment of the MB of planned (ex-ante analysis) or already implemented EEMs (ex-post analysis) within an organization can reveal additional positive cash flows resulting from the effects the EEM has on various business areas. The comprehensive analysis of these effects is only possible by involving key stakeholders from each division, such as upper management, technology officers, energy managers, but also operating staff, users, and even customers. Moreover, the EEM needs to be thoroughly characterized in economic, as well as in technical terms; and the environment in which it is operated needs to be fully specified. The effects of the implemented or the potential EEM on different processes, technologies, or even behavioral aspects can be either assessed (ex-post) or estimated (exante) qualitatively or quantitatively. Quantitative assessment is capable of strongly influencing the investment decision based on its impact on key financial indicators such as the payback time, the net present value, or the internal rate of return. The more favorable these values are, the more likely it is that the EEM is regarded on the same level as an investment concerning the core business; and hence, energy efficiency projects can be compared and coordinated with other pending investments within an organization.

The development of the MB methodology involved several steps, initially starting with the analysis of the drivers and barriers for the implementation of EEMs. The next step 


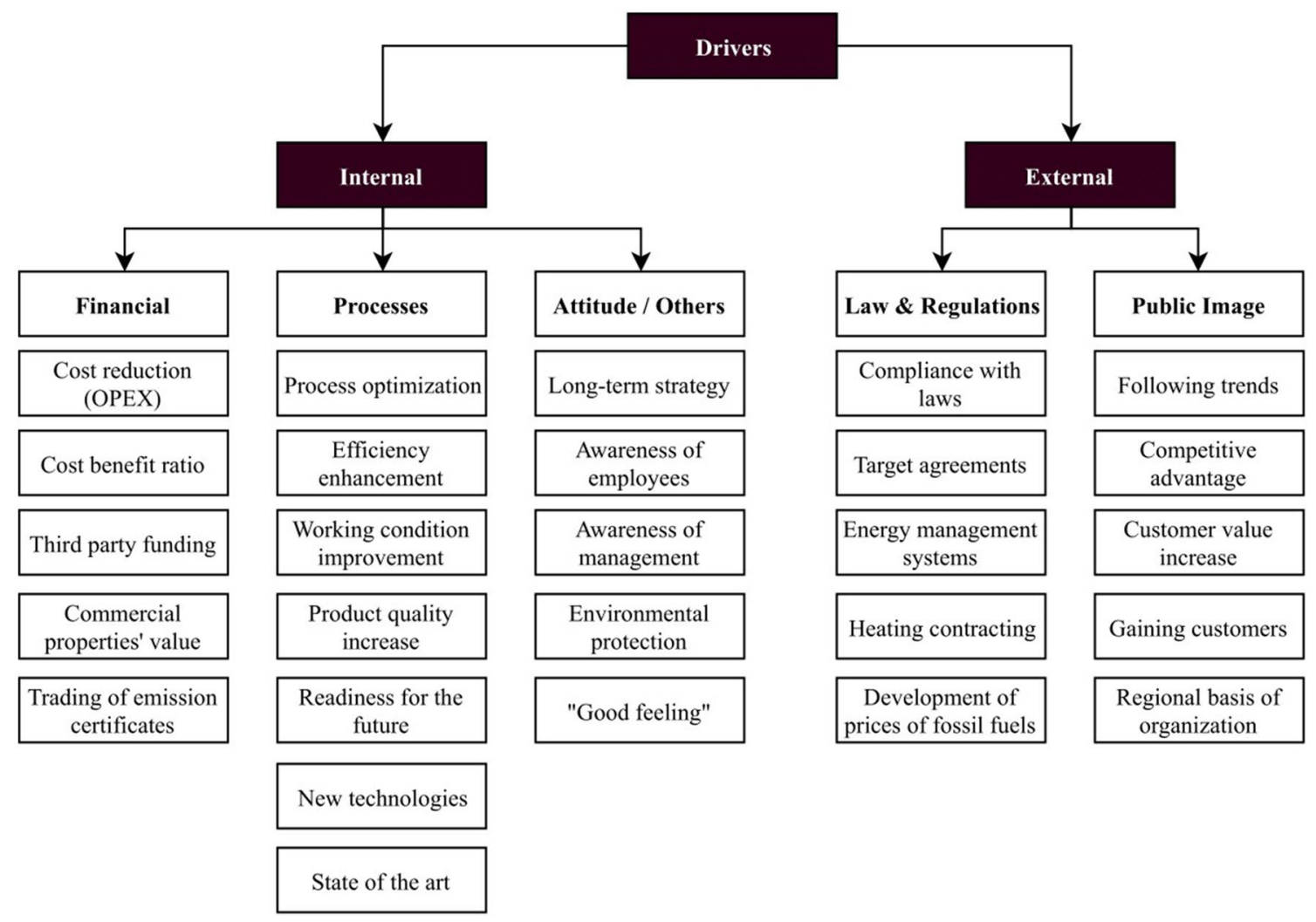

Fig. 1 Drivers for the implementation of EEMs

was to define an overview of all potential MB which could occur in industrial processes. Based on this knowledge, the three phases of the actual MB methodology were defined.

\subsection{Analysis of drivers and barriers}

The definition of a methodology, which is applicable in an industrial setting and sustains the market in the long run, requires, amongst numerous other factors, the consideration of the stakeholder requirements. This, in turn, involves knowledge of decision processes within organizations and-most importantly-the analysis of relevant drivers and barriers for the implementation of EEMs. Figures 1 and 2 list the most relevant drivers and barriers for the implementation of EEMs as synthesized from three large-scale studies investigating the drivers and barriers in various organizations across Europe $[8,9,11]$. Comparable drivers and barriers can also be found at Haraldsson and Johansson [28] and Cagno et al. [27]. Most of the drivers and barriers from the literature were also stated and confirmed by industry partners in the course of the case studies conducted for this research.

Subsequently, the drivers, as well as the barriers, were allocated to internal and external factors. External factors, be it drivers or barriers, cannot be influenced or changed by an organization, while most internal factors can be influenced directly by an organization. This means that internal drivers can be used to encourage the implementation of an EEM by revealing the positive effects the EEM can have on these factors. Enhancing the drivers and, therefore, the positive effects of the implementation of an EEM can lead to synergy effects, which then help to facilitate the implementation of EEMs significantly. Internal barriers, on the other hand, are those factors, most of which can be directly influenced by an organization. Therefore, they provide a lever for the implementation of EEMs. However, the positive effects of external drivers can be used to foster the implementation of EEMs. The internal factors were further split into financial, processual, and other factors. For the external factors, however, it was distinguished between laws and regulations, and public image.

Amongst the barriers, no factors that were associated with the class public image were found. This leads to the conclusion that companies do not seem to see threats concerning their customer relations when implementing EEMs, but contrary, they appear to consider the implementation of EEMs as beneficial for their external image. While the drivers are more equally distributed across internal and external factors, the barriers mostly seem to root inside the organizations. Moreover, analysis of the literature [8, 


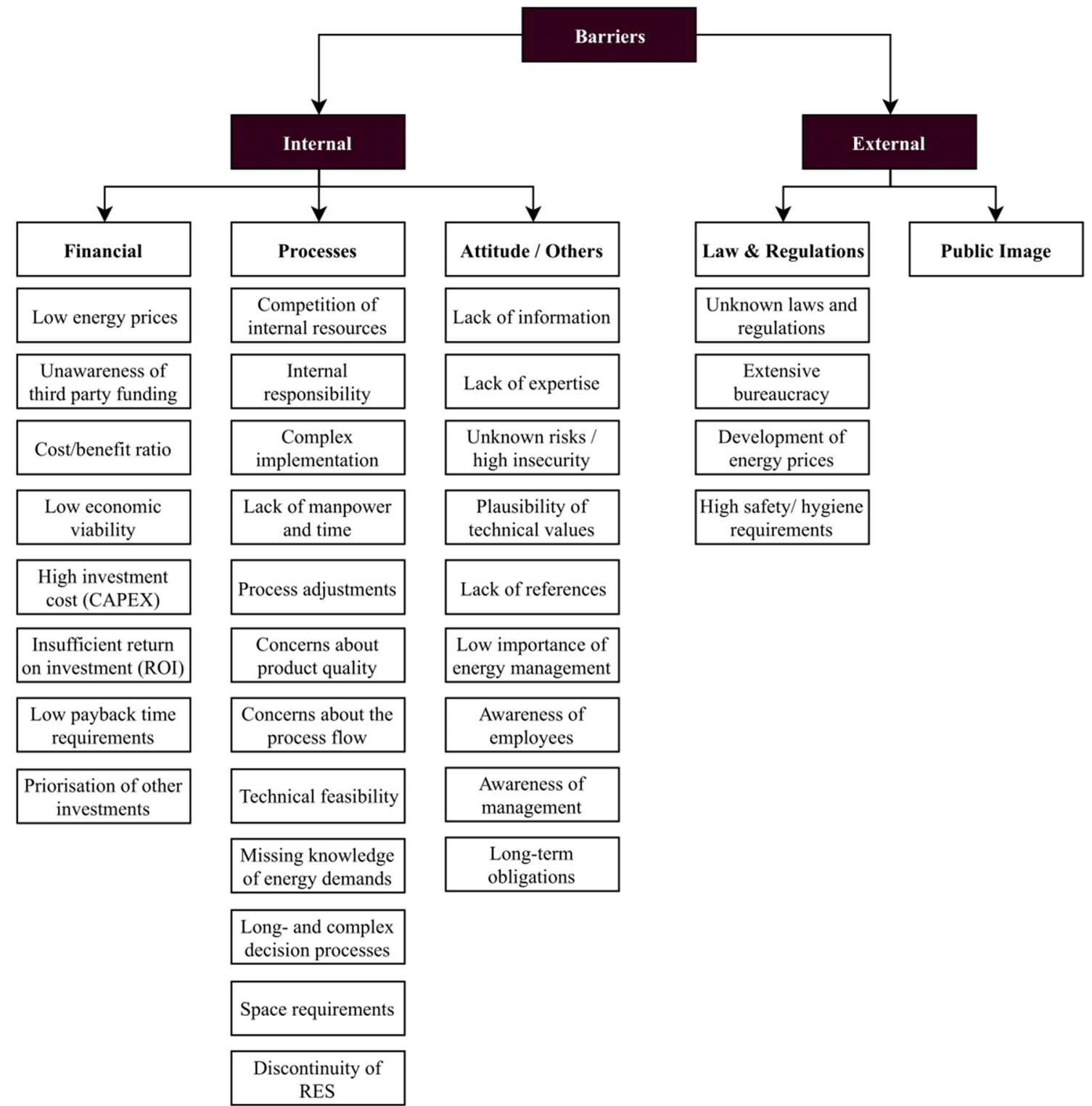

Fig. 2 Barriers to the implementation of EEMs

$9,11]$ showed that the majority of drivers and barriers are the same for different industrial sectors and are independent of the size of a company or a department, while the perceived relevance of the individual drivers and barriers is company dependent.

Understanding the drivers and the barriers that occur for the implementation of EEMs is vital for the development of a comprehensive methodology, which is capable of addressing the specific problems of the organizations in terms of energy efficiency enhancement. Considering that the majority of barriers are internal, and therefore can be influenced by an organization, the effect of an approach eliminating or diminishing most of the barriers can be significant. The presented MB methodology has been conceptualized in such a way that driving factors are supported and barriers reduced.

\subsection{Determination of multiple benefits}

Before the development of the individual stages of the $M B$ methodology, specific key performance indicators (KPIs) were used as a basis for the definition of potential $M B$, which could occur in industrial processes. For an initial set of more than $150 \mathrm{KPIs}$, which were defined based on literature review $[15,18,29]$ in the field of operations management, it was evaluated how a potential benefit could occur through either increase or decrease of the respective value. A typical example of such a KPI is 
Table 1 Overview of selected multiple benefits: clusters (in bold), categories (in italic), and examples

\begin{tabular}{lc}
\hline Public image & Assets \\
Marketing & Machines and equipment \\
External communication & Average machine/equipment capacity utilization \\
Market understanding & Unplanned machine/equipment downtimes \\
Benchmarking & Machine hour cost \\
Best practice establishment & Buildings \\
Organizational sustainability & Work environment \\
Products and services: & Room climate \\
Product acceptance & Vehicle fleet: \\
Product/services sales volume & Fleet size \\
& Yearly mileage \\
Operations & Resources-waste-emissions \\
Production processes & Resource availability \\
Rolled throughput yield & Hazardous waste \\
Overall equipment effectiveness & Greenhouse gas potential of energy carrier emissions \\
Production flexibility & Mitigation costs \\
Logistics & \\
Warehouse capacity utilization & \\
Warehousing costs & Water \\
Human resources & Water recovery rate \\
Employee health and safety & Water consumption \\
Human resources costs &
\end{tabular}

capacity utilization: the increase of a machine's capacity utilization could result in higher production rates, which in turn would cause higher revenue and therefore yield additional benefits. In a further step, duplicates, overlapping KPIs, KPIs that could neither be quantified nor reasonably qualified or such only applicable to an extremely narrow range of cases were sorted out.

Further alignment with existing literature (see literature review), as well as the findings from the case studies performed (see case studies and results), reduced the set of KPIs to a final selection of 71 different factors, which are in the following referred to as $\mathrm{MB}$ (the list of the $71 \mathrm{MB}$ can be found in the "Appendix"). To logically structure the defined MB, they were clustered and categorized following two approaches. On the one hand, Michael Porter's value chain model, which is based on the process view of an organization [30], was used. On the other hand, previous research of the SCCER EIP, ${ }^{1}$ which had the purpose of

\footnotetext{
1 SCCER-EIP stands for Swiss Competence Centers for Energy Research - Efficiency of Industrial processes, which is a national funding instrument for energy research financed and coordinated by Innosuisse, the Swiss National Science Foundation, and the Swiss Federal Office of Energy. The SCCER-EIP is one of eight SCCERs and focuses on challenges such as process optimization, process heat from renewable energy and waste heat, and the facilitation of the industry to develop advanced concepts and innovations. The funding period of the SCCER-EIP is $2013-2020$ [32].
}

creating a catalog of implemented EEMs in Swiss industrial companies [1], was used as a source for the categorization.

The defined set of MB has been organized in seven thematic clusters (e.g.: human resources, water, regulatory and operations) and has been allocated further to different categories (e.g.: production processes, logistics and marketing). Table 1 presents an overview of the MB with the clusters (in bold) and categories (in italic). Clusters that are not further separated into sub-categories are given in bold-italic. From the total selection of $71 \mathrm{MB}$ (see "Appendix"), the most significant MB in terms of their occurrence and their potential impact on the profitability of the evaluated EEM have been obtained from the performed case studies and are listed as examples in their respective category.

All of the 71 defined MB (see "Appendix") were assessed based on whether they can be quantified and monetized. For MB equally or similarly defined as industrial KPIs, this was done employing current quantification concepts, which were directly adopted for the given MB. For newly defined MB, quantification concepts were created based on literature and in close collaboration with the industry partners, with which the case studies (see chapter case studies and results) had been performed. Thirty-five MB were found to be both quantifiable and monetizable. Another $15 \mathrm{MB}$ were found to be only quantifiable but not monetizable, while the remaining $34 \mathrm{MB}$ could neither be 
Fig. 3 Three-stage multiple benefits methodology

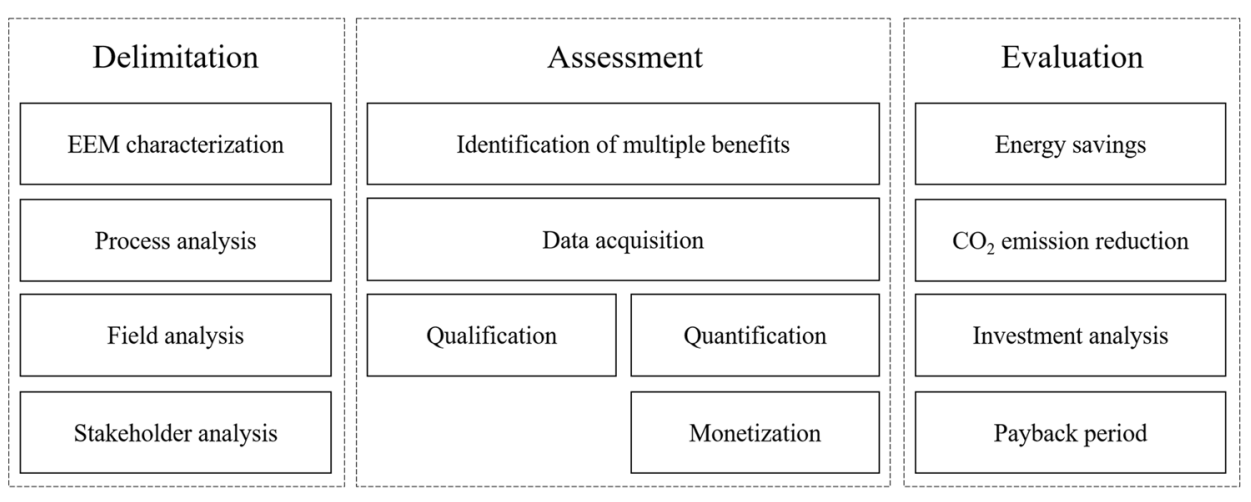

quantified nor monetized and thus need to be assessed qualitatively.

\subsection{Phases of the multiple benefits methodology}

The developed MB methodology differentiates itself from existing methodologies and frameworks, whose focus mainly lies on how the EEM can be embedded for it to appear as equally attractive as other investments that directly influence the critical business activities. The presented MB methodology resembles a 'bottom-up' approach in which the focus lies on the technical aspects of the EEM as well as on the tangible and intangible effects on any relevant processes and activities.

The MB methodology involves three main phases, which are further divided into eleven individual steps, as shown in Fig. 3. These steps are recommended to be performed consecutively to achieve the best results when assessing MB of an EEM. An integral part of the MB methodology is a software-based tool, which aims at supporting and facilitating the assessment of the MB of EEMs by the partly automated analysis of EEMs for a wide range of industrial processes and independent of the industrial sector.

The first phase of the MB methodology is the delimitation phase and consists of four individual steps. The delimitation phase mainly serves to obtain an understanding of the company's organizational structure, the key stakeholders, all relevant processes affected by the implemented/ potential EEMs, and in particular, the technical and economic features of the EEM(s).

The first step of the delimitation phase-EEM characterization-aims at the thorough techno-economic characterization of the EEM and does not consider any tender or dependent processes, stakeholders, or other factors that may influence the EEM or may be influenced by the EEM. This initial characterization includes the collection of the system and company-specific economic data such as the investment cost of the EEM, the organization's discount rate, the expected system lifetime, and the depreciation.
The required technical specifications include, but are not limited to; the specific energy consumption, the system efficiency, the nominal power, and any additionally occurring material or energy flows. The second step-process analysis-focuses on the identification and the detailed analysis of directly affected and directly dependent processes and activities, including the evaluation of related energy- and material flows, and of relevant operating parameters. The third step-field analysis-is of significant importance to understand the overall system within which the EEM is being incorporated, and to know which processes and activities are secondarily affected by the dependent processes and activities. Therefore, all indirectly affected processes and activities are identified and characterized based on their key parameters. Interviews, as well as the in-depth study of process maps, have shown to be the most effective tools to complete these two steps. The last step of the delimitation phase is the stakeholder analysis, which is conducted based on the findings from the previous steps. It serves to complete the overall picture of the examined system and to understand the influence of each stakeholder within and outside the organization on the implementation of the EEM. The most suitable tool in this step is the stakeholder map [31], which rates the stakeholders based on their interest, their influence and their impact concerning the EEM.

The second phase-assessment phase-focuses on the identification, the quantification, and the monetization of all MB associated with the characterized EEM. The first step of the assessment phase is dedicated to the identification of the MB, which are defined to be relevant from a technical, economic, and societal point of view. Based on the knowledge gained in the delimitation phase, and in close collaboration with relevant stakeholders, a preliminary set of $M B$ is defined. Therefore, two subsequent steps are followed: (1) From the complete list of all $71 \mathrm{MB}$ (see "Appendix") that have been determined in the course of this research, a first selection is made. (2) This selection is then prioritized to choose the essential MB based on the stakeholder analysis and their respective preferences. 
To assess the identified MB qualitatively or quantitatively as well as in monetary terms, a significant amount of data is necessary. The required type and quality of data depend on the type of MB identified, and most are of technical or economic nature. For the data acquisition, various methods have shown to be practicable: interviews, analysis of performance reports and historical data, reading out of meters, on-site observations, and others.

Whenever MB are monetizable, its monetary value is added to the cash flow resulting from the yearly energy savings. Another suitable option is the expression of the monetized MB in terms of $€$ per saved kWh of energy. All quantifiable $\mathrm{MB}$ are calculated via their percentage change since the actual benefit results from the favorable difference between the value before (i.e., its ante value) and the value after the implementation of an EEM (i.e., its post value). Hence, MB are always to be considered the percentage increase or decrease of a particular value associated with the implementation of an EEM. For all quantifiable and monetizable $M B$, it is essential to distinguish between direct and indirect quantifiable and monetizable benefits: Direct quantification of direct monetization respectively, means that the $\mathrm{MB}$ can be calculated directly from given values such as, e.g., operating times, human resource costs, sales, and others. This applies, e.g., for the MB machine hour costs, employee training costs or warehousing costs. Indirect quantification or monetization occurs whenever no direct values are available, and different approaches such as, e.g., surveys, ratings, or weighting factors are required for the assessment. An example of indirect quantified $\mathrm{MB}$ is the work environment in terms of the workplace, tools and general circumstances under which the work has to be performed (e.g.: teamwork, especially hot environments, etc.). These MB can neither be quantified nor monetized. The latter mostly results in unitless indices, which can then be used to calculate the percentage change between the ante and the post value of the respective benefit. This is the case for MB such as wear and tear of equipment or water contamination. For those MB, which can neither be quantified nor monetized, different assessment methods must be applied. In many cases, there is the option to evaluate these intangible MB qualitatively, i.e., based on their relative change.

Often, different $\mathrm{MB}$ require similar or equal input values to be calculated. Special attention must be given to the potential overlap of certain MB to avoid multiple accounting of single values, which would vitiate the results and therefore diminish the plausibility of the methodology.

The third and last phase of the MB methodology is referred to as the evaluation phase. It focuses on the analysis of all results obtained in the course of the delimitation and the assessment phase. Generally, the energy savings in [MWh/a] and the $\mathrm{CO}_{2}$ emission reductions in [t/a] are not considered to be additional benefits, but they are the actual primary effects aimed for and achieved by the implementation of the EEM. The energy savings, as well as the emission reductions, can be expressed in monetary terms, which is the cash flow on which the initial calculation of the critical financial indicators is usually based. Subsequently, the investment analysis is performed under consideration of the additional cash flows resulting from the assessment of the associated MB.

The initial investment cost for an EEM is the summation of various investment items such as costs for new buildings, renovation and reconstruction costs, additional equipment and machinery required, IT-systems, licenses, materials, consumables, as well as project costs and overheads. Based on these investment costs and under consideration of the additional cash flows revealed by the assessment of the MB, the critical financial indicators such as the payback time, the net present value, as well as the internal rate of return are determined, allowing to assess EEMs at the same level as strategic investments.

\section{Case studies and results}

In the course of the development of the MB methodology, a total of nine case studies have been performed with partners from different industrial sectors in Switzerland between 2016 and 2018. The case studies were selected based on already implemented EEMs, with the aim of covering a broad spectrum of different thermal and electrical EEMs. In total, eight different EEMs (compare Table 2) with either electrical or thermal saving potential were analyzed for the method development and validation. Overall, 48 individual $M B$ were identified in the course of the case studies and a total of $19 \mathrm{MB}$ could be monetized based on available data, which were provided and confirmed by the companies. While the results of earlier cases were mainly used for the development of the methodology, those cases performed at a later stage of the research primarily served for the validation of the underlying concepts and the methodology itself. A full list of all identified MB, including a short description and the respective quantification potential, can be found in the "Appendix".

The investment costs for the EEMs in the cases described in Table 2 ranged between $€ 200$ and $€$ $10,000,000$, while the yearly energy savings ranged from $300 \mathrm{kWh} / \mathrm{a}$ to almost $6 \mathrm{GWh} / \mathrm{a}$. In eight of the nine cases, the assessment of the associated MB yielded significant additional positive cash flows. In absolute values, the additional cash flows ranged from 300 to $1,750,000 € / a$.

The additional cash flows, resulting from the assessment of the MB associated with the implemented EEM, revealed a reduction of payback times of $40-85 \%$ for seven 
Table 2 Case studies: summary of results

\begin{tabular}{|c|c|c|c|c|c|c|c|}
\hline$\#$ & Industry & EEM & Focus & $\begin{array}{l}\text { Energy } \\
\text { savings } \\
{[\mathrm{MWh} / \mathrm{a}]}\end{array}$ & $\begin{array}{l}\text { Number of } \\
\text { MBs identi- } \\
\text { fied }\end{array}$ & $\begin{array}{l}\text { Payback time } \\
\text { with MBs [a] }\end{array}$ & $\begin{array}{l}\text { Reduction of } \\
\text { payback time } \\
(\%)\end{array}$ \\
\hline A & Food and beverages & Boiler replacement (oil) $^{\mathrm{a}}$ & Thermal & 1200 & 9 & 2 & 60 \\
\hline B & & Boiler replacement (gas) $^{a}$ & Thermal & 5800 & 13 & 2 & 85 \\
\hline $\mathrm{C}$ & & Boiler replacement (wood) ${ }^{a}$ & Thermal & 2200 & 13 & 3 & 85 \\
\hline $\mathrm{D}$ & & Filling line replacement ${ }^{b}$ & Electrical & 1900 & 26 & 9 & 80 \\
\hline $\mathrm{E}$ & & Heat recovery system ${ }^{c}$ & Thermal & 150 & 11 & 1 & - \\
\hline $\mathrm{F}$ & Automotive & Illumination system replacement ${ }^{d}$ & Electrical & 2.2 & 4 & 3 & 50 \\
\hline G & & Compressor system replacement ${ }^{\mathrm{e}}$ & Electrical & 0.3 & 6 & 4 & - \\
\hline $\mathrm{H}$ & Construction & Gravel plant optimization ${ }^{f}$ & Electrical & 60 & 30 & 1 & 85 \\
\hline I & Construction & Bitumen temperature optimization $^{g}$ & $\begin{array}{l}\text { Electri- } \\
\text { cal and } \\
\text { thermal }\end{array}$ & 190 & 15 & 1 & 40 \\
\hline
\end{tabular}

\footnotetext{
${ }^{a}$ Replacement of an old boiler for hot water generation with a new system, including an integrated preheater

${ }^{b}$ Replacement of an old filling line. The replacement of a filling line in a production process is not necessarily to be considered an EEM. However, the replacement of the filling line in this particular case leads to a significant amount of energy that could be saved every year

'Stock room heating, warm water system, heat exchanger

${ }^{d}$ Replacement of the light source with new LED lamps and adjustment of the illumination concept in the exhibition room

${ }^{\text {e}}$ Replacement of the compressed air system in the workshop

${ }^{f}$ This EEM consists of a bundle of four individual measures taken in order to improve the overall energy efficiency of the entire gravel plant consisting of two single processes "Brechseite" and "Rundseite" (breaking side and round side), which designates the production of two different qualities of gravel

${ }^{9}$ This EEM considers the temperature stabilization of bitumen during the process
}

of the nine cases. Two of the nine cases (E\&G), however, did not reveal additional cash flows, even though MB were identified in the course of the project. In these two cases, only qualitative MB could be identified which could not be expressed in monetary terms.

\section{Discussion and recommendations}

The principal aim of the MB methodology as it is presented here is to facilitate the implementation of EEMs in industrial settings by providing a standardized methodology, which supports decision-making by considering all effects (i.e., the MB) an EEM has on the different business areas within an organization. The need for such a facilitation method emerged from the fact that often EEMs are not implemented even though they are financially viable. The idea to assess the profound effects of an EEM on different business levels has not developed only recently but has been a relevant topic for at least the last three decades. However, so far, a comprehensive methodology to assess the MB of an EEM in a structured, standardized and applicable manner was missing; the presented MB methodology aims to close this gap.

Although the methodology was developed in a structured way and broken down into its most essential phases - delimitation, assessment, and evaluation - a full assessment of the MB of an EEM can remain complex and resource-intensive. Especially when new processes and EEMs are considered, or when various dependent processes encompass the systems, the analysis can become highly complex. Moreover, the close involvement of all key stakeholders requires a high level of organization to meet all requirements. However, a steep learning curve is anticipated considering the implementation of similar EEMs within similar processes in the same or similar industries. Further research involves the definition of clear guidelines for a simple representation of the methodologies' applicability in industry. An integral part of these guidelines will be dedicated to addressing organizations and those responsible in terms of implementing the guidelines within their processes. Therefore, sector-specific guidelines and an MB-supporting tool adapted to sector-specific needs are considered to be significant success criteria for the dissemination of the presented MB-methodology.

The particular relevance of the qualitative multiple benefits, i.e., those which cannot be assessed quantitatively and in monetary terms, remains to be evaluated. Currently considered industry partners rate the monetizable multiple benefits more valuable since they result in cash flows that can directly be offset with the energy-related expenses caused by an EEM. However, 
non-monetizable MB may have a certain character, which means they could tip the scales in the decision for or against the realization of the EEM. Since the effect on the non-quantifiable MB cannot be evaluated, they are reported to the customer as "being likely to improve", "being likely to impair" or as "being unlikely to change". At the same, the quantified and monetized MB are not being reported as a fixed value but as a range to account for uncertainties of the results. These uncertainties arise from different sources, such as assumed values obtained from a potentially subjective assessment of experts or varying data quality (i.e. caused by precision and accuracy levels of measured data).

\section{Conclusion}

The primary objective of the MB methodology is to provide a comprehensive and standardized approach for the assessment of MB associated with EEMs in an industrial context. Its focus lies on the technical aspects of the EEM as well as on the tangible and intangible effects of the EEM on any relevant processes and activities. The analysis of these aspects and effects is based on detail, therefore, the potential additional positive cash flows from the identified MB are exploited. The cash flows are offset with the cash flows directly generated from the energy savings.
Eventually, the results obtained are used as an instrument to communicate with decision-makers.

The analysis of the case studies revealed that various $M B$ occur depending on the industry, the processes and the EEM that was implemented. The amount of MB, occurring as a result of the implementation of an EEM, does not correlate with the actual amount of energy saved. Overall, a reduction of payback times of $40-85 \%$ was achieved through the thorough analysis and inclusion of monetizable MB. Due to its holistic character, the developed methodology to assess $\mathrm{MB}$ of EEMs is applicable in a wide range of industrial processes and sectors. Moreover, the methodology allows covering of all categories and types of potential EEMs in an industrial context. Providing a structured and standardized methodology could be the key to fostering a viable implementation of EEMs in the industry.

Acknowledgements This research project is financially supported by Swiss Innovation Agency Innosuisse and is part of the Swiss Competence Center for Energy Research-Efficiency of Industrial Processes SCCER EIP.

\section{Compliance with ethical standards}

Conflict of interest On behalf of all authors, the corresponding author states that there is no conflict of interest.

\section{Appendix: Identified multiple benefits}

\begin{tabular}{|c|c|c|}
\hline Identified multiple benefits & $\begin{array}{l}\text { Quantifiability/assessment } \\
\text { potential (high, medium, low) }\end{array}$ & Description \\
\hline Human resource costs & High & $\begin{array}{l}\text { The total cost associated with human resources based on yearly work- } \\
\text { ing times, workload, and gross salaries. This MB is directly monetiz- } \\
\text { able and may or may not include the following factors: employee } \\
\text { health and safety, training costs, or other }\end{array}$ \\
\hline Employee health and safety & Medium & $\begin{array}{l}\text { A measure of the employee's health and safety measured by the } \\
\text { number of absences due to illnesses or accidents }\end{array}$ \\
\hline $\begin{array}{l}\text { Employee education and training } \\
\text { costs }\end{array}$ & High & $\begin{array}{l}\text { All costs associated with training and continuing education for } \\
\text { employees, which are partly or entirely paid by the company. This } \\
\text { MB is directly monetizable }\end{array}$ \\
\hline Other cost factors & Factor depending & $\begin{array}{l}\text { Any other cost drivers worth to be taken into account for the determi- } \\
\text { nation of the human resource costs }\end{array}$ \\
\hline Employee satisfaction & Medium & $\begin{array}{l}\text { The qualitative assessment of the employee's satisfaction, e.g. based } \\
\text { on regular surveys. This MB can neither be directly quantified nor } \\
\text { monetized. However, indirect quantification is possible by using } \\
\text { surveys or questionnaires }\end{array}$ \\
\hline Room climate & High & $\begin{array}{l}\text { The qualitative assessment of the room climate in terms of tempera- } \\
\text { ture, humidity, and air movement. This MB can neither be quantified } \\
\text { nor monetized }\end{array}$ \\
\hline
\end{tabular}




\begin{tabular}{|c|c|c|}
\hline Identified multiple benefits & $\begin{array}{l}\text { Quantifiability/assessment } \\
\text { potential (high, medium, low) }\end{array}$ & Description \\
\hline Work environment & Low & $\begin{array}{l}\text { The qualitative assessment of the work environment in terms of work- } \\
\text { place, tools, and general circumstances under which the work has } \\
\text { to be performed (e.g., protective equipment, isolation, teamwork, } \\
\text { especially hot environments, forced postures, noise levels, illumina- } \\
\text { tion quality, etc.). This MB can neither be quantified nor monetized }\end{array}$ \\
\hline $\begin{array}{l}\text { Other factors influencing } \\
\text { employee satisfaction }\end{array}$ & Factor depending & $\begin{array}{l}\text { Any other factors worth to be taken into account for the determina- } \\
\text { tion of employee satisfaction, e.g., benefits, flexibility, part-time } \\
\text { models, home-office, etc }\end{array}$ \\
\hline Customer satisfaction & Low & $\begin{array}{l}\text { The qualitative assessment of the customer's satisfaction based on } \\
\text { regular surveys. This MB can neither be directly quantified nor mon- } \\
\text { etized. However, indirect quantification may be possible, e.g., with } \\
\text { surveys or questionnaires }\end{array}$ \\
\hline Marketing costs & Medium & $\begin{array}{l}\text { The total cost associated with any marketing activities. This MB is } \\
\text { directly monetizable }\end{array}$ \\
\hline Target market share & low & $\begin{array}{l}\text { The total market share measured in a company's sales divided by the } \\
\text { total market sales }\end{array}$ \\
\hline $\begin{array}{l}\text { Influence of organizational } \\
\text { culture }\end{array}$ & Low & $\begin{array}{l}\text { Any measurable or non-measurable influence on the organizational } \\
\text { culture e.g. changes in the communication structures }\end{array}$ \\
\hline Benchmarking & Low & $\begin{array}{l}\text { The comparison of the company's standards with its competitor's } \\
\text { standards }\end{array}$ \\
\hline Competitive advantage & low & $\begin{array}{l}\text { The qualitative assessment of the company's competitive advantage. } \\
\text { This MB can neither be quantified nor monetized }\end{array}$ \\
\hline Best practice establishment & Low & $\begin{array}{l}\text { The qualitative assessment of whether best practices can be estab- } \\
\text { lished and the assessment of the extent to which best practice } \\
\text { establishment helps a company to more success. This MB can } \\
\text { neither be quantified nor monetized }\end{array}$ \\
\hline Organizational sustainability & Low & $\begin{array}{l}\text { The qualitative assessment of a company's sustainability in terms of } \\
\text { economic sustainability, resource management, energy, envi- } \\
\text { ronmental footprint, etc. Organizational sustainability is defined } \\
\text { differently for every company. This MB can neither be quantified nor } \\
\text { monetized }\end{array}$ \\
\hline Sales revenue & High & The yearly sales revenues \\
\hline Production costs & High & $\begin{array}{l}\text { The total cost associated with the production of a product or the } \\
\text { provision of a service. This MB is directly monetizable }\end{array}$ \\
\hline Product/service sales volume & High & The total yearly sales volume of a specific product or service \\
\hline Product/service sales price & High & The price at which a product/service is sold to the customer \\
\hline Contribution margin & High & The selling price per unit less the variable cost of a product/service \\
\hline Demand coverage & Medium & $\begin{array}{l}\text { The rate at which a company's production volume meets the market } \\
\text { demand. The higher this rate, the better the production of the com- } \\
\text { pany is adapted to the customer demand }\end{array}$ \\
\hline Product features or service scope & High & $\begin{array}{l}\text { The qualitative assessment of the features of a product or the scope } \\
\text { of service. This MB can neither be quantified nor monetized }\end{array}$ \\
\hline Product quality & Medium & $\begin{array}{l}\text { The quality of produced products or provide services based on indi- } \\
\text { vidual quality attributes such as e.g., tolerances, color, usability, etc. } \\
\text { This MB does not provide any information about the process quality } \\
\text { (i.e., good products and total produced products) }\end{array}$ \\
\hline Vehicle fleet costs & High & $\begin{array}{l}\text { The total cost associated with maintaining an own vehicle fleet } \\
\text { (trucks, automobiles, other) including insurances, depreciation, } \\
\text { service, parking fees, etc. but excluding fuel costs }\end{array}$ \\
\hline Yearly mileage & High & The total yearly mileage is driven by the entire fleet \\
\hline Building operation costs & Medium & $\begin{array}{l}\text { The total cost associated with the preservation of the adequate } \\
\text { conditions within buildings (e.g., measures to preserve an adequate } \\
\text { room climate and work environment such as meters, controls, sen- } \\
\text { sors, valves, furniture, tools, equipment, etc.) }\end{array}$ \\
\hline Machine/equipment lifetime & High & The technical machine or equipment lifetime \\
\hline
\end{tabular}




\begin{tabular}{|c|c|c|}
\hline Identified multiple benefits & $\begin{array}{l}\text { Quantifiability/assessment } \\
\text { potential (high, medium, low) }\end{array}$ & Description \\
\hline $\begin{array}{l}\text { Replacements of parts within a } \\
\text { lifetime (incl. depreciation) }\end{array}$ & Medium & $\begin{array}{l}\text { Any costs related to the replacement of parts during the lifetime of } \\
\text { a machine/equipment, or at least during the accounting period } \\
\text { considered. It also includes the depreciation }\end{array}$ \\
\hline $\begin{array}{l}\text { Preventive maintenance (w/o } \\
\text { downtimes) }\end{array}$ & High & $\begin{array}{l}\text { Total cost for preventive maintenance actions including materials, } \\
\text { unproductive employees, additional staff and experts, but exclud- } \\
\text { ing the replacement of parts within the lifetime and accounting for } \\
\text { downtimes }\end{array}$ \\
\hline Wear and tear of equipment & Low & $\begin{array}{l}\text { The qualitative assessment of the approximate wear and tear of } \\
\text { equipment. This MB can neither be quantified nor monetized }\end{array}$ \\
\hline $\begin{array}{l}\text { Machine/equipment space } \\
\text { requirement }\end{array}$ & High & $\begin{array}{l}\text { The total floor area, which is used by the machine/equipment. It is } \\
\text { suggested to differentiate between two cases to monetize this MB: } \\
\text { (i) new structures have to be built: offset with total initial investment } \\
\text { cost for the EEM; (ii) space is freed for other purposes or more space } \\
\text { is taken and therefore unavailable for other purposes: determine } \\
\text { effect on cash flow and/or initial investment }\end{array}$ \\
\hline Machine hour cost & High & $\begin{array}{l}\text { The total cost per machine hour when the factory overhead (neglect- } \\
\text { ing direct costs such as labor and direct materials) is divided by the } \\
\text { actual operating time of the machine. This MB is directly monetiz- } \\
\text { able }\end{array}$ \\
\hline $\begin{array}{l}\text { Total effective equipment per- } \\
\text { formance }\end{array}$ & Medium & $\begin{array}{l}\text { A rate to measure manufacturing productivity, i.e., the percentage } \\
\text { of total available time that is genuinely productive. Total effec- } \\
\text { tive equipment performance consists of the overall equipment } \\
\text { effectiveness (process quality, equipment performance, and equip- } \\
\text { ment availability) multiplied by the equipment utilization (i.e., the } \\
\text { percentage of calendar time used for production) }\end{array}$ \\
\hline Process productivity & Medium & $\begin{array}{l}\text { The rate to measure manufacturing productivity, i.e., the percentage } \\
\text { of planned manufacturing time that is truly productive. Overall } \\
\text { equipment effectiveness is the product of process quality, equip- } \\
\text { ment performance, and equipment availability }\end{array}$ \\
\hline Operating time (i.e., run time) & High & $\begin{array}{l}\text { The total time during which the machine is operating and produc- } \\
\text { ing. It consists of scheduled machine time and the planned and } \\
\text { unplanned stops. Scheduled machine time is defined by the pro- } \\
\text { duction plan of an organization and designates the total planned } \\
\text { productive time of the machine. Downtimes are composed of } \\
\text { preventive and corrective maintenance actions, start-up and shut- } \\
\text { down times, cleaning times, and other planned or unplanned stops } \\
\text { during which the machine is not productive }\end{array}$ \\
\hline Unplanned downtimes & Medium & $\begin{array}{l}\text { The downtime of a machine due to corrective maintenance, break- } \\
\text { downs, and other unplanned stops during which the machine is not } \\
\text { productive. Unlike with planned interruptions, unplanned inter- } \\
\text { ruptions involve a loss of profit since the downtime was scheduled } \\
\text { productive and hence value-generating }\end{array}$ \\
\hline Equipment availability & High & $\begin{array}{l}\text { The fraction of the actual operating time (run time) of a machine and } \\
\text { its scheduled machine time (planned production time). The higher } \\
\text { this ratio, the better }\end{array}$ \\
\hline Equipment performance & High & $\begin{array}{l}\text { A measure of the speed at which the work center runs in comparison } \\
\text { to its designed speed }\end{array}$ \\
\hline Process quality & High & $\begin{array}{l}\text { The quality of the process in terms of the ratio of right parts produced } \\
\text { as compared to the total number of parts produced }\end{array}$ \\
\hline Equipment utilization (EU) & High & The planned production time in comparison to the calendar time \\
\hline Production flexibility & Low & $\begin{array}{l}\text { The qualitative assessment of either the operational flexibility to } \\
\text { adjust production volumes to the current demands or of the flex- } \\
\text { ibility to produce different products or product variants using the } \\
\text { same production line }\end{array}$ \\
\hline Rolled throughput yield & High & $\begin{array}{l}\text { The probability that a single unit passes a series of process steps free } \\
\text { of defects, or in other words: The overall production yield in the case } \\
\text { of multiple process steps, i.e., the total production efficiency }\end{array}$ \\
\hline Process cycle time & High & $\begin{array}{l}\text { The total time for one unit to pass through the entire process from } \\
\text { beginning to end }\end{array}$ \\
\hline
\end{tabular}




\begin{tabular}{|c|c|c|}
\hline Identified multiple benefits & $\begin{array}{l}\text { Quantifiability/assessment } \\
\text { potential (high, medium, low) }\end{array}$ & Description \\
\hline Process reliability & Medium & $\begin{array}{l}\text { The ratio of total unplanned interruption time and scheduled } \\
\text { machine time to assess how reliably the process operates without } \\
\text { encountering any problems }\end{array}$ \\
\hline Process automation rate & Medium & The rate at which a process is automated \\
\hline Warehouse capacity utilization & High & $\begin{array}{l}\text { The proportion to which the maximum space available (based on } \\
\text { the maximum warehouse capacity) is used by all stored goods (raw } \\
\text { materials, work in progress, and finished goods) }\end{array}$ \\
\hline Days on hand & High & $\begin{array}{l}\text { A measure for the average number of days an item is held in the } \\
\text { inventory to indicate how well inventory is being managed }\end{array}$ \\
\hline Average stock level & High & The average stock level is maintained at hand throughout the year \\
\hline Inventory value & High & $\begin{array}{l}\text { The cost of unsold inventory at the end of an accounting period (typi- } \\
\text { cally at the end of the fiscal year) }\end{array}$ \\
\hline Warehousing costs & High & $\begin{array}{l}\text { The total cost associated with warehousing, including space, } \\
\text { warehousing activities, equipment, transportation efforts, quality } \\
\text { control, stock losses, and safety }\end{array}$ \\
\hline Product handling & Medium & $\begin{array}{l}\text { The total cost for warehousing activities such as receiving, putting, } \\
\text { moving, picking, sorting, packing, and shipping }\end{array}$ \\
\hline Total resource costs & High & $\begin{array}{l}\text { The total cost associated with resources in terms of the purchase } \\
\text { price, transaction costs, storage costs, and any other costs }\end{array}$ \\
\hline Resource availability & Medium & $\begin{array}{l}\text { The assessment of the availability of resources. Especially useful in } \\
\text { case of rare resources or when the availability is highly dependent } \\
\text { on the current demand }\end{array}$ \\
\hline Risk level of resources & Medium & $\begin{array}{l}\text { The qualitative assessment of the safety risks in terms of health issues } \\
\text { or environmental hazards that could be triggered by resources }\end{array}$ \\
\hline Health risks & Medium & Any health risks related to resources \\
\hline Environmental hazard & Medium & Any environmental hazards related to resources \\
\hline Total water consumption & High & $\begin{array}{l}\text { The quantification of the total yearly water consumption for various } \\
\text { purposes within the company (e.g., process water, cooling water, } \\
\text { domestic water, etc.) }\end{array}$ \\
\hline Water recovery rate & High & $\begin{array}{l}\text { The rate at which the used water is recovered within the company } \\
\text { and reused for the same or other purposes. It has a direct impact on } \\
\text { the yearly freshwater consumption and water disposal. Remark: if } \\
\text { the recovery rate is reduced, the water consumption is most likely } \\
\text { to be reduced at the same time, its monetization then accounts for } \\
\text { both MBs at the same time }\end{array}$ \\
\hline Water contamination & Low & $\begin{array}{l}\text { The assessment of the level of contamination and the type of con- } \\
\text { taminants in the water }\end{array}$ \\
\hline Total cost for waste & High & $\begin{array}{l}\text { The total cost associated with waste in terms of mitigation costs, stor- } \\
\text { age, disposal, treatment, and any other costs }\end{array}$ \\
\hline Risk level of waste & Low & $\begin{array}{l}\text { The qualitative assessment of the safety risks in terms of health issues } \\
\text { or environmental hazards that could be triggered by waste }\end{array}$ \\
\hline Health risks & Low & Any health risks related to waste \\
\hline Environmental hazard & Low & Any environmental hazards related to waste \\
\hline Total cost for $\mathrm{CO}_{2}$ eq-emissions & High & $\begin{array}{l}\text { The quantification of the tons of } \mathrm{CO}_{2} \text {-equivalents emitted by pro- } \\
\text { cesses and operations. This } \mathrm{MB} \text { could also be considered a primary } \\
\text { effect (such as energy savings) }\end{array}$ \\
\hline $\mathrm{CO}_{2}$ taxes & High & $\begin{array}{l}\text { The amount of taxes paid based on the yearly emission of } \mathrm{CO}_{2} \text { equiva- } \\
\text { lents }\end{array}$ \\
\hline $\mathrm{CO}_{2}$ levy exemption & High & $\begin{array}{l}\text { The qualitative assessment of whether the } \mathrm{CO}_{2} \text { levy exemption is } \\
\text { granted. This only applies when } \mathrm{CO}_{2} \text { emission levels are below a cer- } \\
\text { tain threshold. Quantification of this } \mathrm{MB} \text { occurs via the } \mathrm{MBCO}_{2} \text { taxes }\end{array}$ \\
\hline $\mathrm{CO}_{2}$ certificates (trading) & High & The total cost or profit from trading $\mathrm{CO}_{2}$ certificates \\
\hline Total cost for other emissions & Low & $\begin{array}{l}\text { The total cost associated with the emission of any emissions not } \\
\text { being } \mathrm{CO}_{2} \text {-equivalents, including mitigation costs, taxes, fines, etc. }\end{array}$ \\
\hline
\end{tabular}




\begin{tabular}{|c|c|c|}
\hline Identified multiple benefits & $\begin{array}{l}\text { Quantifiability/assessment } \\
\text { potential (high, medium, low) }\end{array}$ & Description \\
\hline $\begin{array}{l}\text { Compliance with target agree- } \\
\text { ments, laws, and quality } \\
\text { systems }\end{array}$ & Medium & $\begin{array}{l}\text { The qualitative assessment of how well a company complies with } \\
\text { target agreements defined (e.g., by the government). This MB can } \\
\text { neither be quantified nor monetized. Includes the extent to which } \\
\text { a company is able to make use of emission certificates for trading } \\
\text { purposes and how good a company complies with standard- and } \\
\text { quality systems }\end{array}$ \\
\hline Granting of reoccurring subsidies & High & $\begin{array}{l}\text { Any form of reoccurring subsidies that occur at project initiation is to } \\
\text { be offset with the investment cost. Onetime subsidy occurring at a } \\
\text { later stage of the project may be considered in the MB assessment }\end{array}$ \\
\hline
\end{tabular}

\section{References}

1. SCCER-EIP (2018) Swiss Competence Centers for Energy Research-Efficiency of Industrial Processes. https://www. sccer-eip.ch/. Accessed 20 May 2019

2. Eurostat (2017) Consumption of energy. https://ec.europ a.eu/eurostat/statistics-explained/index.php/Consumptio n_of_energy. Accessed 11 Jul 2018

3. Umweltbundesamt (2017) Treibhausgas-Emissionen in der Europäischen Union. https://www.umweltbundesamt.de/ daten/klima/treibhausgas-emissionen-in-der-europaeischenunion\#textpart-5. Accessed 23 Jul 2018

4. Swiss Federal Office of Energy (2017) Schweizerische Gesamtenergiestatistik 2017. Bern

5. Swiss Federal Office for the Environment (2018) Klima: Das Wichtigste in Kürze. https://www.bafu.admin.ch/bafu/de/ home/themen/klima/inkuerze.html\#-1439031040. Accessed 27 Jun 2018

6. Rasmussen J (2014) Energy-efficiency investments and the concepts of non-energy benefits and investment behavior. Industrial summer study proceedings: retool for a competitive and sustainable industry, European council for an energy efficient economy 2:733-744

7. OECD/IEA (2014) Capturing the multiple benefits of energy efficiency, Paris, pp 131-187

8. Sres A, Andres J, Nussbaumer B (2018) Erneuerbare Energien in der Industrie-Fallanalysen, Hochrechnung und Empfehlungen

9. Eymann L, Räber M (2013) Projekt "Negawatt statt Megawatt" Literaturstudie über die Erfolgsfaktoren und Hemmnisse bei der Umsetzung von Energie-effizienzprojekten für KMU

10. Cagno E, Moschetta D, Trianni A (2019) Only non-energy benefits from the adoption of EEMs? A novel framework. J Clean Prod 212:1319-1333

11. United Nations (2017) Overcoming barriers to investing in energy efficiency United Nations Economic Commission for Europe, New York and Geneva

12. Mills E, Rosenfeld A (1996) Consumer non-energy benefits as a motivation for making energy-efficiency improvements. Energy 21:521-745

13. Meier A (1983) The cost of conserved energy as an investment statistic. Helv Phys Acta 55:73-77

14. Lilly P, Pearson D (1999) Determining the full value of industrial efficiency programs. In: Proceedings of ACEEE summer study energy efficiency in industries, pp 349-362

15. Pye M, McKane A (2000) Making a stronger case for industrial energy efficiency by quantifying non-energy benefits. Resour
Conserv Recycl 28:169-282. https://doi.org/10.1016/S0921 -3449(99)00042-7

16. Worrell E, Laitner JA, Ruth M, Finman H (2003) Productivity benefits of industrial EEMs. Energy 28:1043-1131

17. Hall N, Roth J (2003) Non-energy benefits from commercial and industrial energy efficiency programs: energy efficiency may not be the best story. In: Proceedings of 2003 international energy program evaluation conference, pp 689-702

18. Lung RB, McKane A, Leach R, Marsh D (2005) Ancillary savings and production benefits in the evaluation of industrial EEMs. In: Proceedings of ACEEE summer study energy efficiency in industries, pp 6-114

19. Skumatz L, Khawaja S, Colby J (2009) Lessons learned and next steps in EEMment and attribution: energy savings, net to gross, non-energy benefits, and persistence of energy efficiency behavior. In: CIEE behavior energy program, p 166

20. Cooremans C (2011) Make it strategic! Financial investment logic is not enough. Energy Effic 4:473-492

21. Cooremans $C$ (2012) Investment in energy efficiency: Do the characteristics of investments matter? Energy Effic 5:497-518

22. Ryan L, Campbell N (2012) Spreading the net: the multiple benefits of energy efficiency improvements, Paris

23. Russell C (2015) Multiple benefits of business-sector energy efficiency: a survey of existing and potential measures, Washington

24. Nehler T, Rasmussen J (2016) How do firms consider nonenergy benefits? Empirical findings on energy-efficiency investments in Swedish industry. J Clean Prod 113:472-482

25. Nehler T (2016) The non-energy benefits of industrial energy efficiency: investments and measures. Linköping University, Sweden

26. Rasmussen J (2017) The additional benefits of energy efficiency investments-a systematic literature review and a framework for categorisation. Energy Effic 10:1401-1418

27. Cagno E, Trianni A, Spallina G, Marchesani F (2017) Drivers for energy efficiency and their effect on barriers: empirical evidence from Italian manufacturing enterprises. Energy Effic 10:855-869. https://doi.org/10.1007/s12053-016-9488-x

28. Haraldsson J, Johansson MT (2019) Barriers to and drivers for improved energy efficiency in the Swedish aluminium industry and aluminium casting foundries. Sustain 11:6-8

29. Pearson D, Skumatz L (2002) Non-energy benefits including productivity, liability, tenant satisfaction, and others-what participant surveys tell us about designing and marketing commercial programs. In: ACEEE summer study on energy efficiency in buildings, pp 289-302 
30. Porter M (1985) Competitive advantage: creating and sustaining superior performance, New York

31. Murray-Webster R, Simon P (2006) Making sense of stakeholder mapping. PM World Today 3:5

32. Innosuisse (2018) Innosuisse-Swiss innovation agency. https:// www.innosuisse.ch/inno/en/home.html. Accessed 25 May 2018
Publisher's Note Springer Nature remains neutral with regard to jurisdictional claims in published maps and institutional affiliations.

\section{SN Applied Sciences}

a SPRINGer NATURE journal 